RESEARCH PAPER

\title{
Exposure to environmental tobacco smoke (ETS) and determinants of support for complete smoking bans in psychiatric settings
}

\author{
M C Willemsen, C A Görts, P Van Soelen, R Jonkers, S R Hilberink
}

Tobacco Control 2004;13:180-185. doi: 10.1136/tc.2003.004804

See end of article for authors' affiliations

............

Correspondence to: Dr M C Willemsen, STIVORO-for a smoke free future, PO Box 16070 2500 BB The Hague, The Netherlands; mwillemsen@ stivoro.nl

Received 4 June 2003 Accepted 28 January 2004

\begin{abstract}
Objective: To measure environmental tobacco smoke (ETS) exposure in psychiatric settings and to assess determinants of support for complete smoking bans.

Design: Cross sectional study

Setting: Dutch psychiatric hospitals, outpatient care institutions, and sheltered home facilities. Subjects: A random sample of 540 treatment staff, 306 attendants/nurses, and 93 patients.

Main outcome measures: Self reported ETS exposure, current smoking policy, compliance with smoking policy, beliefs about smoking bans.

Results: $87 \%$ of respondents were exposed to tobacco smoke in psychiatric institutions; $29 \%$ said that on an average day they were exposed to "a lot of smoke". Although ETS originates mainly from smoking patients, both non-compliance from patients and employees with existing bans resulted in non-smokers being exposed to ETS. Due to non-compliance, ETS exposure was quite high when there is a general smoking ban (designated areas option). Only with a complete ban was compliance good and employees sufficiently protected from ETS exposure. Psychiatrists, psychologists, physicians, attendants, and nurses were most concerned about resistance from patients, partly because of the fear of infringing on patients' freedom to smoke.

Conclusions: Complete smoking bans are the only way to fully protect those working in psychiatry from ETS exposure, mainly because general smoking bans are not sufficiently complied with. Communication strategies to improve compliance with complete bans are crucial to protect those working in psychiatry from ETS. Compliance could be improved by addressing the belief that the ban will effectively result in less ETS exposure and the issue of patients' freedom to smoke versus employees' right to work in a smoke-free environment.
\end{abstract}

M any countries have governmental regulations to protect employees from exposure to environmental tobacco smoke (ETS), which is a risk factor for lung cancer $^{12}$ and heart disease mortality. ${ }^{4}$ When smoking bans are announced, one setting that is often strongly opposed to stricter regulation is psychiatry. Smoking prevalence among psychiatric patients has been estimated at between $50-80 \%$.

Most research on smoking bans in psychiatry has been conducted in the USA. ${ }^{6-13}$ The situation in the USA that triggered these studies was rather exceptional. In 1991, concern about tobacco related diseases led to the enforcement of a complete smoking ban in all US accredited hospitals, ${ }^{14}$ with no exception for psychiatric wards. This intensified the debate about the appropriateness of smoking bans for psychiatry. ${ }^{6}{ }^{10}$ Sixteen months after introduction of the ban, only $43 \%$ of hospitals that offered inpatient psychiatric treatment had smoke-free psychiatric wards. ${ }^{15}$ Reasons why psychiatric institutions had difficulty in implementing the ban were concern that nicotine withdrawal may impair medical treatment ${ }^{16}$ and the expectation that psychiatric patients will not comply with a ban. ${ }^{17}$ Indeed, some studies reported that a smoking ban causes aggressive behaviour in addicted patients, ${ }^{18}$ but given administrative commitment and freely accessible outdoor areas, banning smoking in psychiatric hospitals proved less difficult to implement and maintain than anticipated. ${ }^{6} 7^{9-11} 1317$ Staff attitude toward supporting a ban generally improved after introduction of the ban. ${ }^{6}{ }^{11}$ Although few major disturbances occurred, minor management difficulties have been reported in locked units where severely disturbed patients are treated..$^{8}{ }^{12}$ Consequently, in 1994 US accredited hospitals were permitted to allow patients with a longer than six months stay to smoke without needing a physician's order. ${ }^{19}$ While other countries can learn much from the US experiences, their situation may differ considerably. One important difference occurs when a ban for psychiatry is not part of a hospital ban, but instead is part of general governmental regulations to protect citizens from exposure to ETS in the workplace.

The Netherlands provides a good example. A new smoking Act takes effect in 2004, giving all employees the legal right to work in a smoke-free environment, with no exception for psychiatry. Employers may choose how they protect their employees from ETS. Employers who do not succeed will be subject to financial penalties.

The literature is concentrated on inpatient psychiatric facilities. However, in many countries other forms of psychiatric care are also subject to smoking bans. These are institutions of outpatient care (such as regional institutions for mental health and poli-clinical treatment in psychiatric hospitals or day hospitals), and sheltered homes where patients live outside the boundaries of a hospital. Another source of information that is often overlooked is what patients and personnel other than psychiatrists think of the issue. Previous studies were restricted to psychiatrists ${ }^{16}$ or

Abbreviations: ANOVA, analyses of variance; ETS, environmental tobacco smoke; NIP, Dutch Institute of Psychologists; NVPV, Dutch Association of Psychiatric Nurses; NVSPV, Dutch Association of Social Psychiatric Nurses 
used such a small sample that it was not possible to differentiate between professions. ${ }^{620}$ The present study is the first to use large enough sample sizes to be able to differentiate between professions and between psychiatric settings.

The purpose of the study was to examine which policies were most common, how they were complied with, the amount of ETS exposure, and to explore beliefs determining support for complete smoking bans.

\section{METHODS \\ Subjects}

Random samples from member lists of different vocational groups in Dutch psychiatry were drawn. The group of "treatment staff" was made up of psychiatrists, psychologists, and physicians. Samples of psychiatrists $(n=350)$ and physicians $(\mathrm{n}=378$ ) were randomly selected from a list provided by IMS-Health, a bureau that supplies practice addresses of professionals in the field of mental health for research purposes. Two random samples of psychologists were derived from the NIP (Dutch Institute of Psychologists), one from the outpatient section $(n=150)$, and one from the inpatient section $(n=147)$. Psychiatric nurses, social psychiatric nurses, and group attendants were taken together as one group called "attendants and nurses". Random samples of 150 respondents were selected both from the NVPV (Dutch Association of Psychiatric Nurses) and the NVSPV (Dutch Association of Social Psychiatric Nurses). The sample of group attendants $(n=132)$ was obtained by sending a request to the directors of all 44 sheltered accommodation facilities, to the effect that three group attendants from each facility participate. All subjects received a letter, with a request to participate in a survey, which took about 15 minutes to complete. A compact disc with classical music was enclosed as an incentive.

By law, each psychiatric institution in the Netherlands must set up a patient council that represents patients' interests so that patients have a say in their own living and treatment conditions. These councils provide an excellent way of collecting patient data. A total of 200 councils were randomly selected from a register of all patient councils. They received a letter with the request to participate in the survey. Councils were free to fill in the questionnaire jointly or to appoint one member to complete the questionnaire.

Subjects were not evenly distributed among all settings: physicians were from inpatient settings, all group attendants were working in sheltered home facilities, and psychiatrists and psychologists worked in inpatient and outpatient settings.

\section{Measurements}

Data collection occurred between May and September 2000 using self report questionnaires.
Smoking behaviour was measured by asking "Do you ever smoke?" and "Do you yourself smoke at your place of work/ in your institution?" (five-point scales: "always"-"never").

Current smoking policy was assessed according to international classifications ${ }^{21-23}$ by the question "How is smoking by employees and patients regulated in your institution?". Respondents could choose between: (a) Smoking in the institution is entirely at the discretion of the employees/ patients (No explicit policy); (b) There is no ban on smoking except in some general areas that are open to all employees and patients (Moderate smoking restriction); (c) Smoking is restricted to designated areas (General no-smoking policy); (d) Smoking is not permitted anywhere in our institution (Complete smoking ban); (e) Don't know. Smoking policy was measured with respect to both employees and patients.

Compliance with smoking policy was assessed with: "How well do employees/patients comply with the regulations regarding smoking at your institution/ward?" Answers were "very well" (2) to "very poorly" (-2). Compliance was asked with respect to both employees and patients.

Exposure to ETS was measured using three items: "How often are you bothered by smoke in your institution?"; "How frequently do others smoke in your presence during your work/in your institution?" (always (4)-never (0)); and "How much environmental tobacco smoke, on average, is there during a day at your work/in your institution?" $(0=$ no smoke, $1=$ very little smoke, $2=$ a little smoke, $3=$ not much/not little, $4=$ quite a lot of smoke, $5=$ a lot of smoke, 6 = an awful lot of smoke). The last item has been shown to correlate highly with actual nicotine concentrations. ${ }^{24}$ The three items were summed to a scale of "exposure to ETS" with Cronbach's $\alpha=0.84$.

Preferences for type of smoking policy were assessed with four statements. "It should be completely left to the employees and patients where and when they smoke at the institution"; "A smoking ban should only be applied to public areas, whereas in all other facilities (including the place of work) everyone should be free to smoke"; "Smoking should be allowed only in special smoking areas"; "There should be a smoking ban for the entire institution". Subjects could respond on a four point scale (strongly agree-strongly disagree).

Beliefs about the consequences of smoking restrictions in psychiatry were explored by two questions: "Which important advantages does a more restrictive smoking policy have?" and "Which important disadvantages does a more restrictive smoking policy have?". More than one answer was allowed. There were six advantages and 10 disadvantages with yes/no answer options. Finally, two beliefs that were important in Dutch psychiatry were assessed: "Do you think that smoking has a calming effect on the patients?" ("strong effect", "some effect", "no effect") and "You cannot take away

Table 1 Background characteristics of respondents

\begin{tabular}{|c|c|c|c|}
\hline Variable & $\begin{array}{l}\text { Treatment staff } \\
\text { (540) }\end{array}$ & $\begin{array}{l}\text { Aftendants and } \\
\text { nurses (306) }\end{array}$ & Patients (93) \\
\hline Male (\%) & 54.5 & 45.2 & $63.9^{* *}$ \\
\hline Mean (SD) age & $43.2(9.3)$ & $42.0(7.2)$ & $43.2(11.5)$ \\
\hline \multicolumn{4}{|l|}{ Setting (\%) } \\
\hline Inpatient & 77 & 36 & $41^{\star * *}$ \\
\hline Outpatient & 23 & 33 & 24 \\
\hline Sheltered homes & 0 & 31 & 34 \\
\hline & 31.4 & 26.2 & $55.3^{\star * \star}$ \\
\hline \multicolumn{4}{|c|}{ Smoking (at least sometimes) in the institution } \\
\hline$(\%) \dagger$ & 18.2 & 21.0 & $59.5^{\star \star \star}$ \\
\hline
\end{tabular}


Table 2 Association between type of psychiatric setting and current smoking policies, compliance with policies, and ETS exposure (employees + patients)

\begin{tabular}{|c|c|c|c|c|c|}
\hline & $\begin{array}{l}\text { Inpatient (a) } \\
(\mathrm{n}=553)\end{array}$ & $\begin{array}{l}\text { Outpatient (b) } \\
\text { ( } n=244)\end{array}$ & $\begin{array}{l}\text { Sheltered } \\
\text { homes (c) } \\
(n=119)\end{array}$ & $\begin{array}{l}\text { Total } \\
(n=916)\end{array}$ & Significance \\
\hline $\begin{array}{l}\text { Mean exposure to ETS (range 0-14) } \\
\text { Current smoking policy for employees }(\%)^{*}\end{array}$ & 4.9 & 3.4 & 7.3 & 4.8 & $\begin{array}{l}\mathrm{b}<\mathrm{a}<\mathrm{c} \ddagger \\
<0.001\end{array}$ \\
\hline No explicit policy & 5 & 8 & 13 & 6 & \\
\hline Moderate smoking restriction & 20 & 24 & 32 & 22 & \\
\hline $\begin{array}{l}\text { General no-smoking policy (smoking only allowed in } \\
\text { designated areas) }\end{array}$ & 64 & 46 & 47 & 56 & \\
\hline Complete smoking ban & 10 & 21 & 8 & 12 & \\
\hline Don't know & 1 & 1 & 0 & 3 & \\
\hline Current smoking policy for patients (\%) & & & & & $<0.001$ \\
\hline No explicit policy & 9 & 5 & 52 & 14 & \\
\hline Moderate smoking restriction & 14 & 13 & 23 & 15 & \\
\hline General no-smoking policy & 68 & 50 & 20 & 57 & \\
\hline Complete smoking ban & 6 & 26 & 1 & 10 & \\
\hline Don't know & 3 & 6 & 4 & 4 & \\
\hline Employee compliance with smoking policyt(\%) & 51 & 62 & 67 & 56 & $<0.001$ \\
\hline Patient compliance with smoking policy† (\%) & 52 & 74 & 57 & 58 & $<.001$ \\
\hline
\end{tabular}

patients' cigarettes." (five point scale: strongly agreestrongly disagree).

\section{Statistical analyses}

The research questions were analysed first by univariate comparisons across study groups, using $\chi^{2}$ analyses and analyses of variance (ANOVA), where appropriate. Differences in exposure, current policy, and compliance with policy were examined across the three settings (psychiatric hospitals, institutions of outpatient care, and sheltered accommodation). Preferences for smoking policy and attitudes towards smoking bans were compared across treatment staff, attendants/nurses, and psychiatric patients. Determinants of exposure to ETS and of preference for smoking bans were examined with linear regression analyses and logistic regression analyses, respectively. Data were analysed with SPSS statistical package.

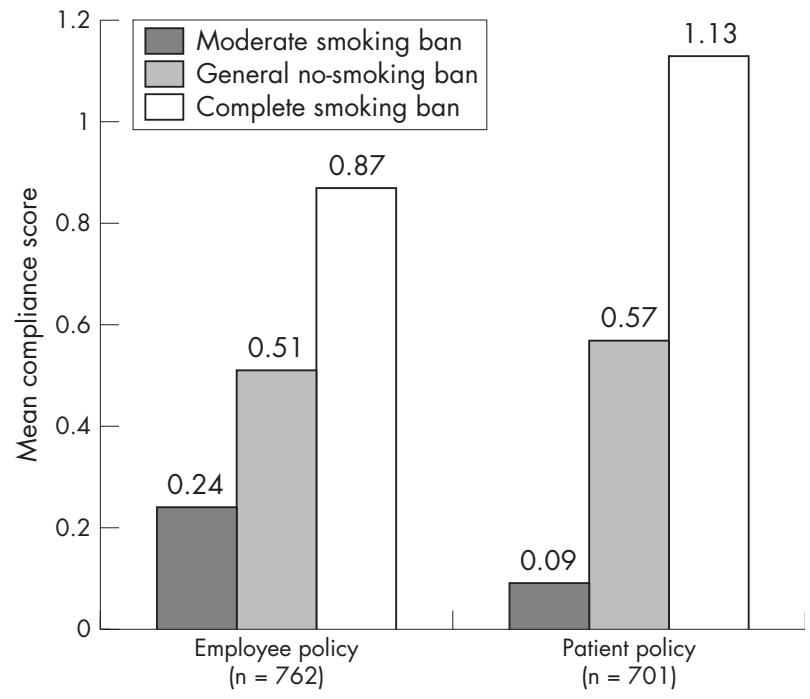

Figure 1 Employee compliance with employee policy and patient compliance with patient policy. Note: Respondents are smoking and non-smoking employees. Missing are "no policy" and "don't know" answers scale range: $-z$ (very poor compliance) to $+z$ (very good compliance). All differences between groups are significant $(p<0.001)$.

\section{RESULTS}

\section{Response}

The response rates were $54 \%$ for psychiatrists, 52\% for psychologists in outpatient settings, $60 \%$ for psychologists in inpatient settings, $49 \%$ for physicians, $69 \%$ for psychiatric nurses, $66 \%$ for social psychiatric nurses, $79 \%$ for group attendants, and $47 \%$ for patients.

\section{Characteristics of study samples}

Table 1 shows age, sex distribution, and smoking behaviour. More than half of psychiatric patients were smokers (55\%). Smoking was less common among treatment staff (31\%) and attendants/nurses (26\%). Eighteen per cent of treatment staff and $21 \%$ of attendants and nurses smoked at their place of work, compared to $59 \%$ of all patients. Some of the patients reported they were "non-smokers", but said they did smoke in the institution (sic!).

\section{Employee exposure to ETS}

Across the three settings, $29 \%$ of non-smoking employees were never bothered by smoke at their institution, and $28 \%$ said that others never smoked in their presence during work.

Thirteen percent of non-smokers answered that there was never any tobacco smoke during an average work day, whereas $29 \%$ said they were exposed to "a lot of smoke/very much smoke". ETS exposure varied considerably between the settings.

Among smokers who do not smoke in their institution themselves, we found that $47 \%$ was never bothered by smoke at their institution, $28 \%$ said that others never smoked in their presence during work, and 17\% answered that there was never any tobacco smoke during an average work day.

Table 2 shows the results for the three item exposure scale (all respondents taken together). Exposure was highest in the sheltered homes, followed by psychiatric hospitals, and outpatient settings $(\mathrm{F}(2,841)=50.7 ; \mathrm{p}<0.001)$.

\section{Current smoking policy}

Across all settings, $12 \%$ of institutions had a complete smoking ban for employees and $10 \%$ had a complete smoking ban for patients as well (table 2). Most respondents reported that there was a general smoking policy at their worksite or place of residence. The patient smoking policy in sheltered 


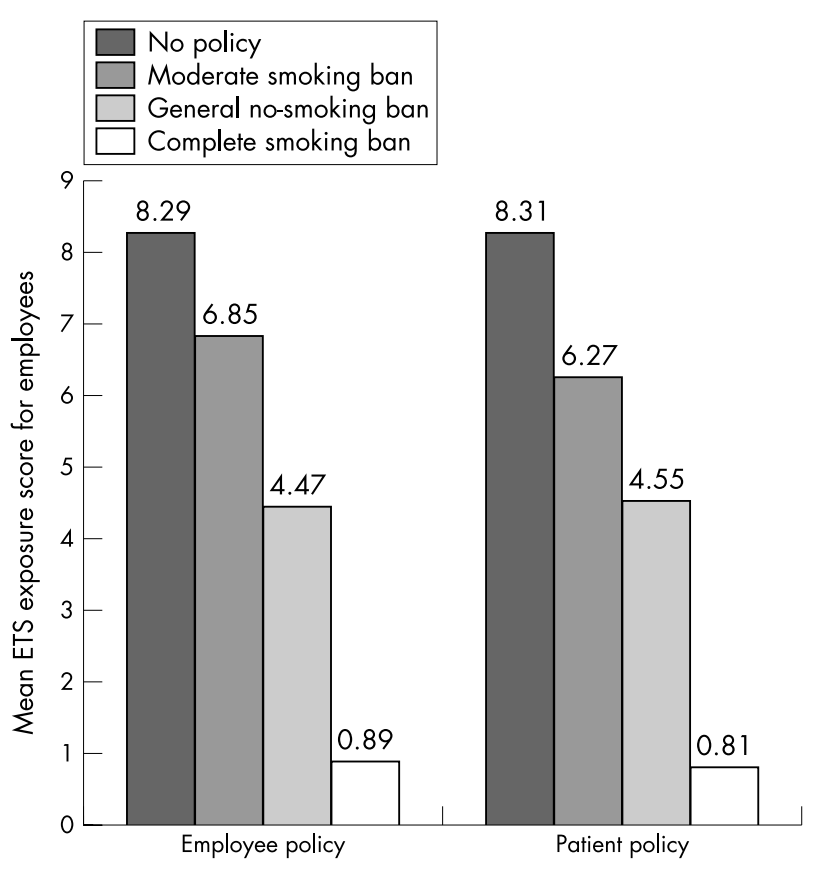

Figure 2 Association between employee ETS exposure and current employee smoking policy and current patient smoking policy ( $n=568$ non-smoking employees; 22 missing because of "don't know" answers).

homes differed from other settings; $52 \%$ had no explicit smoking policy for patients.

\section{Compliance}

Employee compliance with the current policy was comparable to patient compliance: $56 \%$ of employees and $58 \%$ of patients complied (table 2). For both groups, compliance was lowest in inpatient settings. Both patient and employee compliance was highest with complete smoking bans (fig 1). Complete smoking bans for employees and patients were much more protective than general smoking bans (fig 2).
A regression analysis showed that ETS exposure was highest in inpatient settings, among nurses and among smokers (table 3). Exposure was negatively associated with being a psychiatrist, having a smoking policy in place (compared to having no smoking policy), and higher compliance. Smoking policies for employees and for patients both contributed to reduced ETS exposure among employees. The total variance explained was 53\%.

\section{Preferred smoking policy}

Preferences for smoking policies differed between employees and patients (table 4). Two thirds of employees preferred a general no-smoking policy, compared to $45 \%$ patients. Employees choose a complete smoking ban as a second best option (19\%), whereas patients more often favoured no explicit policy $(18 \%)$ or did not agree with any option $(20 \%)$.

\section{Beliefs concerning a smoking ban}

The most frequently cited advantages of smoking bans were a healthier work environment, less annoyance from ETS, and clarity about where smoking is allowed (table 4). Overall, treatment staff saw fewer disadvantages than attendants/ nurses and patients. The three groups were most concerned about resistance from patients, distress among patients, and practical problems.

A logistic regression analysis was conducted in which support for a smoking ban was regressed on type of setting, type of profession, smoking behaviour, and the beliefs. The criterion was dichotomised into preference for a complete ban versus all other options. Preference for a complete ban was positively associated with the belief that a ban results in less annoyance from ETS (table 5). Surprisingly, respondents who favoured a complete ban were less likely to think that such a ban would result in more clarity about where and when smoking is allowed. Those supportive of a ban were less afraid of practical problems and they less often thought that you cannot take away a patient's cigarette.

\section{DISCUSSION}

Exposure to ETS is common in Dutch psychiatry. As few as $13 \%$ of respondents were never exposed to tobacco smoke at their institution. This compares very unfavourably to the rest of the Dutch health sector. A recent study showed that $45 \%$ of

Table 3 Determinants of employee exposure to ETS (stepwise regression analysis, final model) $(n=796)$

\begin{tabular}{ll}
\hline Variables & $\boldsymbol{\beta}$ \\
\hline Setting (outpatient = reference category) & $0.10^{* * *}$ \\
Inpatient & 0.14 \\
Sheltered accommodation & $-0.10^{* * *}$ \\
Profession (physician = reference category) & -0.03 \\
Psychiatrists & $0.11^{* * *}$ \\
Psychologists & 0.09 \\
Nurses & $-0.17^{* * *}$ \\
Attendants & $-0.39^{* * *}$ \\
Current policy for employees (no policy= reference category) & $-0.47^{* * *}$ \\
Moderate smoking restriction & $-0.10^{* * *}$ \\
General no-smoking policy & $-0.15^{* * *}$ \\
Complete smoking ban & $-0.20^{* * *}$ \\
Don't know & $-0.22^{* * *}$ \\
Current policy for patients (no policy= reference category) & $-0.13^{* * *}$ \\
Moderate smoking restriction & $-0.23^{* * *}$ \\
General no-smoking policy & $-0.17^{* * *}$ \\
Complete smoking ban & $0.06^{*}$ \\
Don't know & \\
Employee compliance with employee policy & \\
Patient compliance with patient policy & \\
Smoker (no smoker = 0) & \\
\hline *p<0.05; *** $<0.001$. &
\end{tabular}


Table 4 Beliefs about smoking bans for treatment staff, attendants/nurses, and patients

\begin{tabular}{|c|c|c|c|c|c|}
\hline Variables & $\begin{array}{l}\text { Treatment staff } \\
(\mathrm{n}=538)\end{array}$ & $\begin{array}{l}\text { Attendants/ } \\
\text { nurses } \\
(n=304)\end{array}$ & $\begin{array}{l}\text { Patients } \\
(\mathrm{n}=91)\end{array}$ & $\begin{array}{l}\text { Total } \\
(\mathrm{n}=933)\end{array}$ & $\begin{array}{l}\text { Significance } \\
\left(\chi^{2} \text { test }\right)\end{array}$ \\
\hline Preferred smoking policy (\% agree) & & & & & $<0.001$ \\
\hline Doesn't agree with any option & 7 & 11 & 20 & 10 & \\
\hline No explicit policy & 0 & 3 & 18 & 3 & \\
\hline Moderate smoking restriction & 6 & 7 & 9 & 6 & \\
\hline $\begin{array}{l}\text { General no smoking policy (smoking only allowed } \\
\text { in designated areas) }\end{array}$ & 67 & 62 & 45 & 63 & \\
\hline Complete smoking ban & 20 & 17 & 8 & 18 & \\
\hline \multicolumn{6}{|l|}{ Perceived advantages of smoking restrictions (\%) } \\
\hline Healthier work environment & 81 & 88 & 81 & 81 & $<0.001$ \\
\hline Decrease of annoyance from ETS & 66 & 70 & 50 & 66 & $<0.005$ \\
\hline Clarity about where smoking is allowed & 48 & 55 & 51 & 51 & NS \\
\hline Decrease of somatic complaints by patients & 36 & 38 & 23 & 36 & $<0.05$ \\
\hline Decrease of somatic complaints by employees & 35 & 40 & 23 & 35 & $<0.05$ \\
\hline No advantages & 5 & 5 & 15 & 6 & $<0.001$ \\
\hline \multicolumn{6}{|l|}{ Perceived disadvantages of smoking restrictions (\%) } \\
\hline Resistance from patients & 43 & 53 & 60 & 48 & $<0.001$ \\
\hline Provoke patient distress & 36 & 52 & 56 & 43 & $<0.001$ \\
\hline Practical problems & 36 & 46 & 39 & 40 & $<0.05$ \\
\hline Restriction of patients' freedom & 31 & 44 & 48 & 37 & $<0.001$ \\
\hline Resistance from employees & 33 & 40 & 20 & 33 & $<0.005$ \\
\hline Enforcement issues & 30 & 41 & 29 & 33 & $<0.005$ \\
\hline Disruption of patient care & 19 & 24 & 25 & 21 & NS \\
\hline No disadvantages & 23 & 13 & 11 & 19 & $<0.001$ \\
\hline Negative interaction with patients' illness & 10 & 24 & 17 & 15 & $<0.001$ \\
\hline Adverse effects on treatment outcomes & 12 & 12 & 11 & 12 & NS \\
\hline Smoking has a strong calming effect on patients (\%) & & & & & $<0.001$ \\
\hline Strong effect & 9 & 16 & 35 & 14 & \\
\hline Some effect & 65 & 64 & 53 & 64 & \\
\hline No effect & 26 & 20 & 12 & 22 & \\
\hline You cannot take away patients' cigarettes (\% agree) & 36 & 49 & 72 & 44 & $<0.001$ \\
\hline
\end{tabular}

workers in the health sector are never exposed to tobacco smoke. ${ }^{25}$ Moreover, 29\% said that on an average day they were exposed to "a lot of smoke". This is almost 10 times the exposure level that is common in the Dutch health sector in general. ${ }^{25}$

This study showed that ETS is highest in sheltered homes and lowest in outpatient clinics and that it originates for a large part from smoking patients: $59 \%$ of patients smoked at the institution, whereas $18 \%$ of treatment staff and $21 \%$ of attendants/nurses smoked at their place of work. Employee ETS exposure was worse if compliance from either employees or patients with existing regulations was low. This suggests that communication strategies to improve compliance both directed at patients and employees are central to effective protection from ETS in psychiatry.
A strength of the study was the dataset that included various professional groups and patients as well as various psychiatric settings. However, the dataset was not representative of every profession in psychiatry. Specifically, social workers, occupational therapists, and unskilled staff were not represented. Other limitations of the study were that smoking policy and smoking behaviour were self reported. Self reporting of smoking behaviour is known to be slightly biased towards non-smoking. The response rates varied from $47 \%$ for patients to $79 \%$ for group attendants. These response percentages are rather high for this type of study. However, selection bias cannot be ruled out.

We recommend that educational campaigns should be conducted with a view to informing psychiatric institutions about how they can best increase compliance with smoking

Table 5 Determinants of preference for smoking bans: 1 =complete smoking ban $(n=152)$ versus $0=$ all other options $(n=703)$; stepwise logistic regression analysis (final model)

\begin{tabular}{|c|c|c|}
\hline Variables & OR & $95 \% \mathrm{Cl}$ \\
\hline \multicolumn{3}{|l|}{ Setting (outpatient $=$ reference category) } \\
\hline Inpatient & 0.76 & $0.48-1.20$ \\
\hline Sheltered accommodation & 1.04 & $0.48-2.24$ \\
\hline \multicolumn{3}{|l|}{ Profession (patient = reference category) } \\
\hline Treatment staff & 2.11 & $0.64-6.96$ \\
\hline Attendants and nurses & 1.97 & $0.59-6.53$ \\
\hline Smoker (non-smoker $=0$ ) & $0.33^{* * *}$ & $0.19-0.58$ \\
\hline \multicolumn{3}{|l|}{ Beliefs $(0=$ disagree, $1=$ agree $)$} \\
\hline You cannot take away patients' cigarettes & $0.45^{\star \star \star}$ & $0.37-0.54$ \\
\hline Stricter policy will result in decrease of annoyance from ETS & $2.04^{* *}$ & $1.26-3.29$ \\
\hline Stricter policy will result in clarity about where smoking is allowed & $0.56^{*}$ & $0.37-0.85$ \\
\hline Stricter policy will result in practical problems & $0.53^{* *}$ & $0.33-0.82$ \\
\hline
\end{tabular}




\section{What this paper adds}

Previous studies that assessed smoking bans in psychiatry only took the viewpoint of psychiatrists into account and were restricted to psychiatric hospitals. The current study covered the broad field of psychiatry and included various professions and patients.

This study made it clear that only complete smoking bans will protect employees in psychiatry from exposure to environmental tobacco smoke (ETS), mainly because of a lack of compliance both from employees and patients for general smoking bans. Compliance could be improved by addressing two important issues: the belief that the ban will effectively result in less ETS exposure, and the issue of patients' freedom to smoke.

bans. An educational campaign should address the following issues. First, the results showed that how patients will react to a strict smoking ban is very important to treatment staff and attendants/nurses. They are most concerned about resistance from and distress among patients. This has also been found in a US study among psychiatric nurses. ${ }^{26}$ These concerns are, of course, not unfounded. However, at least in inpatient settings, it has been shown that after implementation of complete smoking bans, much less disruptions of patient care occurred than was originally expected. ${ }^{6} 7^{9-11} 1317$ Moreover, our data show that compliance is high in settings with complete bans.

Second, an important determinant of support for a complete ban is the belief that such a ban will effectively result in less ETS exposure. An educational campaign should highlight this fact. It should pay less attention to the belief that a ban will improve clarity about where smoking is allowed, because this belief was negatively associated with support for a complete ban. Moreover, an important belief that is held particularly by many patients, but also by attendants/nurses and some treatment staff, is that it is wrong to take away a patient's right to smoke. This issue of patients' freedom to smoke must be addressed in order to improve compliance with stricter regulation-for example, by stressing the freedom of employees to work in a smoke-free environment. More research may be needed to find effective strategies to do this.

This study showed that ETS exposure is still high with a general smoking ban in place (designated areas option). There are practical problems associated with designated smoking areas resulting in less than optimal protection. Only with a complete ban is the problem of ETS exposure (almost) non-existent. It should therefore be recommended that psychiatric institutions try to implement a complete smoking ban rather than a general smoking ban. Regrettably, a total ban is only favoured by $20 \%$ of staff, $17 \%$ of attendants/nurses, and $8 \%$ of patients, whereas a majority supports a general smoking ban. Psychiatric institutions that implement general smoking policies must be aware that they need to overcome the problems of compliance and inadequate smoking rooms, otherwise the problem of ETS exposure is not adequately solved and under the new Dutch Act they risk legal penalties.

\section{ACKNOWLEDGEMENTS}

This research was made possible by a grant from the Dutch Health Research and Development Council (ZON-MW).

\section{Authors' affiliations}

M C Willemsen, P Van Soelen, STIVORO-for a smoke free future, The Hague, The Netherlands

C A Görts, R Jonkers, Rescon Research and Consultancy, Haarlem, The Netherlands

S R Hilberink, Centre for Quality of Care Research (WOK), University Medical Centre St Radboud, Nijmegen, The Netherlands

\section{REFERENCES}

1 Bofetta P, Agudo A, Ahrens W, et al. Multicenter case-control study of exposure to environmental tobacco smoke and lung cancer in Europe. J Natl Cancer Inst 1998;90:1440-50.

2 Hackshaw AK, Law MR, Wald NJ. The accumulated evidence on lung cancer and environmental tobacco smoke. BMJ 1997;315:980-8.

3 He J, Vupputuri S, Allen K, et al. Passive smoking and the risk of coronary heart disease: A meta-analysis of epidemiological studies. N Engl J Med 1999;340:920-6.

4 Law MR, Morris JK, Wald NJ. Environmental tobacco smoke exposure and ischaemic heart disease: an evaluation of the evidence. Br MedJ 1997;315:973-80.

5 Hughes JR. Possible effects of smoke-free inpatient units on psychiatric diagnosis and treatment. J Clin Psychiatry 1993;54(3): 109-14.

6 Taylor NE, Rosenthal RN, Chabus B, et al. The feasibility of smoking bans on psychiatric units. General Hospital Psychiatry 1993;15:36-40.

7 Beemer BR. Hospital psychiatric units. Nonsmoking policies. J Psychosoc Nurs Ment Health Serv 1993;31(4): 12-4.

8 Greeman M, McClellan TA. Negative effects of a smoking ban on an inpatient psychiatry service. Hosp Community Psychiatry 1991;42:408-12.

9 Haller E. McNiel DE, Binder RL. Impact of a smoking ban on a locked psychiatric unit. J Clin Psychiatry 1996;57:329-32.

10 Parks JJ, Devine DD. The effects of smoking bans on extended care units at state psychiatric hospitals. Hospital and Community Psychiatry 1993;44:885-6.

11 Patten CA, Bruce BK, Hurt RD, et al. Effects of a smoke-free policy on an impatient psychiatric unit. Tobacco Control 1995;4:372-9.

12 Ryabik BM, Lippmann SB, Mount R. Implementation of smoking ban on a locked psychiatric unit. General Hospital Psychiatry 1994; 16:200-4.

13 Velasco J, Eels TD, Anderson R, et al. A two-year follow-up on the effects of a smoking ban in an inpatient psychiatric service. Psychiatric Services 1996;47:869-71.

14 Longo DR, Brownson RC, Kruse RL. Smoking bans in US hospitals: results of a national survey. JAMA 1995;274:488-91.

15 Joseph AM, Knapp JM, Nichol KL, et al. Determinants of compliance with a national smoke-free hospital standard. JAMA 1995;274:491-4.

16 Landow L, Szetela B, Know MA. Reducing smoking among psychiatric inpatients: a survey of psychiatrists. Am J Public Health 1995;85:1169.

17 Dawley HH, Williams JL, Guidry LS, et al. Smoking control in a psychiatric setting. Hospital and Community Psychiatry 1989;40:1299-301.

18 Pearlman T. Impact of a smoking ban on a locked psychiatric unit. J Clin Psychiatry 1997;58:179.

19 Appelbaum PS. Do hospitalised psychiatric patients have a right to smoke? Psychiatric Services 1995;46:653-60.

20 Mester R, Toren P, Ben-Moshe Y, et al. Survey of smoking habits and attitudes of patients and staff in psychiatric hospitals. Psychopathology 1993;26:69-75.

21 US Department of Health and Human Services. The health consequences of involuntary smoking. A report of the Surgeon General, 1986. Rockville, Maryland: Public Health Service, Centers for Disease Control, 1986. (DHHS Publication No (CDC) 87-8398.)

22 Jeffery RW, Kelder SH, Forster JL, et al. Restrictive smoking policies in the workplace: effects on smoking prevalence and cigarette consumption. Prev Med 1994;23:78-82.

23 Willemsen MC, De Vries H, Genders R. Annoyance of environmental tobacco smoke and support for no-smoking policies in eight large Dutch workplaces. Tobacco Control 1996;5:132-8.

24 Willemsen MC, Brug J, Uges DRA, et al. Validity and reliability of selfreported exposure to environmental tobacco smoke in work offices. J Occup Environ Med 1997;39:1111-4.

25 Segaar D, Willemsen MC. Exposure to environmental tobacco smoke in Dutch occupational sectors. The Hague: STIVORO, 2003.

26 Buchanan CR, Huffman C, Barbour VM. Counseling of psychiatric patients. J Psychosocial Nursing 1994;32(1):27-32. 